\title{
Prevalence of Lens Opacities in North India: The INDEYE Feasibility Study
}

\author{
Gudlavalleti V. S. Murthy, ${ }^{1}$ Sanjeev K. Gupta, ${ }^{1}$ Giovanni Maraini, ${ }^{2}$ Monica Camparini, ${ }^{2}$ \\ Gill M. Price, ${ }^{3}$ Mukesh Dherani, ${ }^{3}$ Neena Jobn, ${ }^{1}$ Usha Chakravarthy, ${ }^{4}$ and \\ Astrid E. Fletcher ${ }^{3}$
}

Purpose. To obtain estimates of the prevalence of lens opacities in an Indian setting by using photographically acquired lens images.

Methods. In 11 randomly sampled villages from a rural district of Haryana, North India, 1443 people (median age 60 years), $52 \%$ women, were identified from enumeration of the $\geq 50$ year age group; $87 \%$ attended an eye examination. Digital images of cortical and posterior subcapsular opacities and photographs of nuclear opacities were graded using the Lens Opacity Classification System (LOCS) II. The prevalence of opacities was based on a grade of 2 or higher in the worse eye for nuclear, cortical, or posterior subcapsular opacities.

Results. Of the participants, 1071 people had gradable images; a further 163 had undergone surgery or had dense opacities. Nuclear opacities were the most common type, with an overall prevalence of $56.9 \%$ (95\% CI, 53.0-60.6). Posterior subcapsular opacities occurred in 20.6\% (95\% CI, 17.9-25.8) and cortical opacities in $21.6 \%$ (95\% CI, 17.9-25.8). Prevalence rose steeply with age for all opacities and was higher in the women than in the men for cortical opacities $(P=0.03)$. The prevalence of any type of lens opacity including surgical cases and dense opacities was 75.3\% (95\% CI, 71.4-78.81).

Concussions. These results highlight the substantial excess of lens opacities in India compared with Western populations. (Invest Ophthalmol Vis Sci. 2007;48:88-95) DOI:10.1167/ iovs.06-0284

S everal studies have consistently confirmed the high burden $\checkmark$ of blindness due to cataract in the Indian population, especially in the older age group, ${ }^{1-4}$ with estimates of a $5 \%$ or more prevalence of cataract blindness in those 50 years of age and older. $^{2-4}$ Although significant improvements have been attained through the National Programme for Control of Blindness, ${ }^{5}$ there remain significant challenges in both the costs and

From the ${ }^{1}$ Department of Community Ophthalmology, Dr. Rajendra Prasad Centre for Ophthalmic Sciences, All India Institute of Medical Sciences, New Delhi, India; the ${ }^{2}$ Dipartimento di Scienze OtorinoOdonto-Oftalmologiche e Cervico Facciali, Sezione di Oftalmologia, Università degli Studi di Parma, Italy; the ${ }^{3}$ Department of Epidemiology and Population Health, London School of Hygiene and Tropical Medicine, United Kingdom; and the ${ }^{4}$ Department of Ophthalmology and Vision Science, The Queen's University of Belfast, Northern Ireland, United Kingdom.

Supported by Wellcome Trust Grant number 066082

Submitted for publication March 16, 2006; revised June 26, and August 21, 2006; accepted November 14, 2006.

Disclosure: G. V. S. Murthy, None; S. K. Gupta, None; G. Maraini, None; M. Camparini, None; G. M. Price, None; M. Dherani, None; N. John, None; U. Chakravarthy, None; A. E. Fletcher, None The publication costs of this article were defrayed in part by page charge payment. This article must therefore be marked "advertisement" in accordance with 18 U.S.C. $\$ 1734$ solely to indicate this fact.

Corresponding author: Astrid E. Fletcher, Department of Epidemiology and Population Health, London School of Hygiene and Tropical Medicine, London, UK; astrid.fletcher@1shtm.ac.uk. delivery of cataract surgery and in service access and utilization, especially by the most disadvantaged groups in the population. ${ }^{6}$ Forecasts for the increase of elderly people in the Indian population raise further concerns about the feasibility of attaining high surgical coverage, especially given the burden of resources and costs necessary to meet the growing need. Identification of major risk factors for cataract in the Indian setting will therefore be crucial to identifying strategies to reduce or delay the development of this condition. The studies required will use population-based designs (because of the selection biases of those who attend the hospital) and should include a complete ascertainment of the lens status of the eye, to characterize both the degree of opacification and the type of opacities. To date, there have been no population-based studies in India that have provided photographic evidence of lens opacities and none from the hot and dry region in the northern part of the country. The present paper reports the prevalence of lens opacities from a feasibility study conducted in 2003 in Haryana State, North India.

\section{Methods}

The INDEYE feasibility study was a single-center, population-based survey of persons living in a rural periurban region of Balbagarh, Faridabad district, which is a geographically distinct area with a homogeneous and stable population in Haryana, North India, serviced by a community outreach hospital of the All India Institute of Medical Sciences, New Delhi.

The objectives of the feasibility study were to test the acceptability of the study protocol and obtain estimates of the prevalence of lens opacities and age-related macular degeneration (AMD) in preparation for a future larger study in India on the prevalence and risk factors for AMD and cataract. The sampling basis for the study was the 1991 census $^{7}$ (2001 census data were not available at the time) with enumeration of people 50 years of age and older through a door-to-door household survey. A list of 25 rural villages in the catchment area of Balbagarh hospital was obtained from the 1991 census data, and 11 villages were randomly selected. The projected sample size of the feasibility study was 1300 people aged 50 and older (expected to be $13 \%$ of the population) based on an estimated prevalence of late AMD of $2 \%$ with $\pm 1 \%$ at $95 \% \alpha$ and assuming a $90 \%$ response rate.

Before enumeration, meetings were held with local village leaders to explain the study objectives and methods. The study included 1443 people aged $\geq 50$ years who were identified from enumeration and invited to take part. Recruitment into the study was performed in the 4-month period between September 2002 and January 2003. The study complied with the guidelines in the Declaration of Helsinki. Participants who were illiterate had the information leaflet read to them, and subjects were enrolled in the study only after informed written consent (for illiterate participants this consisted of a thumb impression) was obtained. The study received ethics approval from the Research Ethics Committees of the All India Institute of Medical Sciences, the London School of Hygiene and Tropical Medicine and The Queen's University of Belfast.

Investigative Ophthalmology \& Visual Science, January 2007, Vol. 48, No. 1 Copyright (c) Association for Research in Vision and Ophthalmology 


\section{Ophthalmic Procedures}

Visual acuity (VA) was recorded for each eye separately with retroilluminated tumbling-E optotypes, with the subject wearing habitual spectacles (if any). If VA in either of the two eyes of a participant was worse than logMAR 0.6, refraction with an autorefractor (Nikon, Tokyo, Japan) and retinoscopy were performed, and best corrected acuity was recorded. A clinical examination of each eye was performed that included anterior and posterior segment assessments with slit lamp biomicroscopy. Pupillary dilation was performed with $1 \%$ tropicamide after anterior segment biomicroscopy.

The ophthalmic team (one clinical ophthalmologist and two ophthalmic technicians) was trained by two of the authors (GM, MC) in the methods of lens photography. Two different systems were used to obtain lens images after attaining a pupillary dilation of at least $6 \mathrm{~mm}$ : Neitz CT-S (Kowa Optimed Inc., Torrance, CA) for acquiring noncolored digital retroillumination images (two for each eye: one focused on the anterior and the other on the posterior lens surface) to capture cortical and posterior subcapsular (PSC) opacities and Topcon SL-7E (Topcon Corp., Tokyo, Japan) slit lamp for acquiring color slide photographic images to capture nuclear opacities. Photography took place in a windowless room with artificial illumination. Before undertaking the study, we sent the Topcon SL-7E camera to the Department of Ophthalmology, University of Wisconsin (Madison, WI), for modification of the slit lamp beam, to ensure comparability with other eye surveys using this method of lens photography. The slit width and height were fixed at 0.3 and $9.0 \mathrm{~mm}$, respectively, and the slit beam was locked at an angle of $45^{\circ}$ at the photographer's left. Grading of the slides and of digital images was performed by the two ophthalmic technicians in Delhi using the Lens Opacities Classification System (LOCS) II. $^{8}$ Grading was performed by side-by-side comparison with LOCS II standards placed on a uniformly illuminated background. For the grading of cortical and PSC opacities, digital retroillumination images were displayed on a computer screen and adjusted in size to that of the LOCS II standards to facilitate comparison. No digital enhancement methods were used. All members of the ophthalmic team were trained by the authors (GM, MC) and achieved a satisfactory standard in grading. At the first quality-control session during training, the weighted $\kappa$ agreements of the two graders with expert graders (GM, MC) based on 30 photographs (from a standard set held at the University of Parma, for training purposes) for each type of opacity were: cortical opacities ( 0.69 and 0.69 , respectively), nuclear opacities
(0.68 and 0.87), and PSC opacities (0.78 and 0.66). After the final training session, the $\kappa$ values based on 14 photographs were: cortical (0.90 and 0.90 , respectively), nuclear (0.71 and 0.60$)$, and PSC (0.83 and 0.71 ) opacities. During the study, each grader sent photographs from 20 eyes (last five photographs every two weeks of fieldwork) to Parma for independent grading. Weighted $\kappa$ values were cortical $(0.84$ and 0.76 , respectively), nuclear (0.95 and 0.78$)$ and PSC (0.93 and $0.93)$.

\section{Statistical Analysis}

The prevalences of cortical and posterior subcapsular opacities were based on the Neitz-CTS images and that for nuclear opacities on the Topcon slit lamp camera photographs. We used the grade in the worse eye and also categorized opacities as definite cataract according to grade 2 or more for nuclear, cortical, or PSC opacities. Participants who could not be photographed because of very dense opacities were included in the estimates for any type of cataract (as defined earlier). People who were bilaterally pseudophakic or aphakic or who were unilaterally pseudophakic or aphakic with the fellow eye ungradable were included in the estimates for any opacities or past cataract surgery. We included only people with photographed opacities in the tables for type of opacity or cataract, because people with surgically treated cataracts or with dense opacities could not have a type assigned to them. Age- and gender-specific prevalences of types of cataract and their corresponding 95\% confidence intervals (CIs) were calculated taking account of cluster sampling in the calculation of standard errors. Odds ratios for the association with age and gender were estimated by using logistic regression for survey data (Stata; ver. 8$)$.

\section{Results}

The sociodemographic characteristics and response rates are shown in Table 1 . In 11 villages, 1443 people (mean age, 62 years, $52 \%$ women) were enumerated. Of these 3 died before invited to participate and 1 left the area; 1260 (87.6\%) had an eye examination. Photographs were gradable in at least one eye for nuclear opacities for 1071 (85\%) participants and cortical and PSC opacities for 1061 (84\%). Gradings for all three types of opacity were completed in 1051 (83\%) people. The main reasons for no grading were: aphakic/pseudophakic in

TABLE 1. Demographic Characteristics of Surveyed Population

\begin{tabular}{|c|c|c|c|}
\hline Characteristics & $\begin{array}{l}\text { Enumerated } \\
(n=1443)\end{array}$ & $\begin{array}{c}\text { Examined } \\
(n=1260)\end{array}$ & $\begin{array}{l}\text { Lens Grading* } \\
\quad(n=1071)\end{array}$ \\
\hline Male & $693(48.0)$ & $589(46.7)$ & $507(47.3)$ \\
\hline Female & $750(52.0)$ & $671(53.2)$ & $564(52.7)$ \\
\hline \multicolumn{4}{|l|}{ Age groups (y) } \\
\hline $50-59$ & $626(43.4)$ & $539(42.8)$ & $515(48.1)$ \\
\hline $60-69$ & $447(31.0)$ & $393(31.2)$ & $340(31.8)$ \\
\hline$\geq 70$ & $370(25.6)$ & $328(26.0)$ & $216(20.2)$ \\
\hline \multicolumn{4}{|l|}{ Marital Status } \\
\hline Currently married & $1071(74.2)$ & $926(73.5)$ & $830(77.5)$ \\
\hline \multicolumn{4}{|l|}{ Land Holdings } \\
\hline No Land Holdings & $449(31.1)$ & $376(29.8)$ & $319(29.8)$ \\
\hline$>10$ acres land & $103(7.1)$ & $96(7.6)$ & $80(7.5)$ \\
\hline \multicolumn{4}{|l|}{ Literacy Status } \\
\hline Illiterate & $1000(69.3)$ & $886(70.3)$ & $730(68.2)$ \\
\hline \multicolumn{4}{|l|}{ Caste } \\
\hline Backward & $292(20.2)$ & $252(20.0)$ & $215(20.1)$ \\
\hline \multicolumn{4}{|l|}{ Occupation } \\
\hline Housework & $544(37.7)$ & $491(39.0)$ & $436(40.7)$ \\
\hline Cultivation & $357(24.7)$ & $321(25.5)$ & 303 (28.3) \\
\hline Others & $542(37.6)$ & $448(35.5)$ & $332(31.0)$ \\
\hline
\end{tabular}

Percentages in parentheses are based on the denominator in the heading of each column.

* Lens grading available in at least one eye for nuclear opacities. 
both eyes $(n=58)$ or in one eye but with missing lens grade in the other eye $(n=16)$; bilateral dense opacities $(n=93)$; and miscellaneous other reasons $(n=22)$; such as failure to achieve pupillary dilation, phthsis, patient refusal, or missing photographs.

The socioeconomic characteristics of the population were as expected from the census distribution for the state; $31 \%$ did not possess any cultivable land; $69 \%$ were illiterate $(93 \%$ of the women and $43 \%$ of the men); $20 \%$ were classified as from the backward caste; and 38\% were engaged solely in household work and $25 \%$ in cultivation. The demographic characteristics of the population who were enumerated, examined, and graded were similar (Table 1).

The prevalence of all grades of types of lens opacities showed that only a very small number were graded as 0 for nuclear opacities (8.5\%) whereas for cortical and PSC opacities between one half to three fourths, respectively, were graded as 0 (Fig. 1). Of the 1051 people with gradable data on all three opacities and using the criteria for cataract described herein, $27 \%(n=285)$ had mixed cataracts, $35 \%(n=372)$ had only one type of cataract, and $37 \%(n=394)$ had no cataracts. The proportions with mixed cataracts were: nuclear and PSC $(9.9 \%$, $n=104)$, cortical and PSC $(0.6 \%, n=6)$, cortical and nuclear $(7.6 \%, n=80)$, and all three types $(9.0 \%, n=95)$. For pure types, the proportions were: PSC alone ( $1 \% n=10)$, cortical only $(4.5 \%, n=47)$, and nuclear only ( $n=30.0 \%, n=315)$. Of 20 people with missing PSC and cortical grades, 15 had nuclear cataract, and of 10 people with missing nuclear grades, 4 had PSC only and 1 had cortical only. Considering all those defined as having a type of cataract irrespective of whether it was pure or mixed, nuclear cataract was observed in more than one half overall $57 \%(n=594)$ and cortical and PSC in 22\% ( $n$ $=228)$ and $20 \%(n=215)$, respectively (Table 2$)$. The prevalence of any cataract was $73 \%$ when dense ungradable opacities were included and $75 \%$ when those with aphakia or pseudophakia were included. Based on all people who underwent an eye examination, $9 \%(n=111)$ had undergone cataract surgery in one eye, and a further 5\% $(n=58)$ had undergone bilateral surgery (Table 2). Bilateral dense opacities that could not be graded were observed in $6.3 \%(n=37)$ of the men and $8.3 \%(n=56)$ of the women. The prevalence rose steeply with age for all types of cataract and especially for

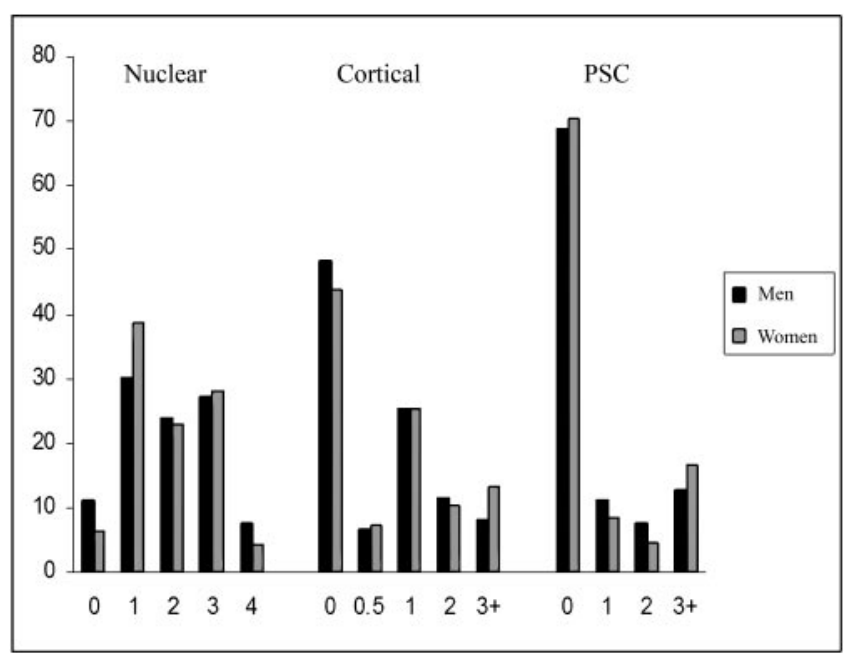

FIGURE 1. Prevalence (\%) of people with grades of opacity by type of opacity and sex. Opacity grades were categorized by the grade of the worse eye. Proportion for each type of opacity based on the number of people with lens photography available for that type of opacity: nuclear, $n=1071$ ( 507 men, 564 women); cortical, $n=1061$ (508 men, 553 women); PSC cataract, $n=1061$ (508 men, 553 women). nuclear cataract. These associations were not changed in additional analyses with adjustment for sex. In age-adjusted analyses, there was a significant association for women with cortical opacities (odds ratio $[\mathrm{OR}]=1.6, P=0.03$ ) but not for other types of opacity or when surgically treated cases were included (Table 3).

\section{Discussion}

In 1999, the World Health Organization (WHO) and the International Agency for Prevention of Blindness embarked on a global initiative called Vision 2020: The Right to Sight. ${ }^{10}$ One of the key elements of this initiative is the provision of successful and sustainable cataract services, as cataract is the commonest cause of blindness worldwide. ${ }^{11}$ Previous studies have documented that the age-adjusted prevalence of cataract in India was three times that in the United States. ${ }^{12}$ A nationwide survey conducted in India over the period 1986 to 1989 revealed that the prevalence of blindness was $1.49 \%$, with a visual acuity cutoff of $<6 / 60$ in the better eye on presenting vision and that $80.1 \%$ of this blindness could be attributed to cataract. ${ }^{13}$ Population-based surveys in recent years have reported that the prevalence of blindness among the $\geq 50$-year group ranges from $6 \%$ to $11.9 \%$ and that cataract is the identifiable cause of blindness in $55 \%$ to $70 \%$ of the blind, with a VA $<6 / 60$ used as the cutoff. ${ }^{1,14}$ Estimates of cataract blindness in these studies were based on a clinical examination by a trained ophthalmologist. However, there was no photographic evidence of the lens status, and therefore it was not possible to identify the different categories of cataract. A strength of the present study is that lens photographs were taken and graded subsequent to the clinical examination without the stress of performing the grading in clinic conditions. In addition, quality control of the photographs and grading was maintained by independent expert examiners (GM, MC).

Our results for the prevalence of lens opacities in Haryana, North India, are very similar to those reported from a recent population-based study in South India: the Aravind Comprehensive Eye Study (ACES). ${ }^{15}$ In that study, based on LOCS III grading at the slit lamp, ${ }^{16}$ the prevalence of nuclear opacities among those aged $\geq 50$ years was $67.7 \%$ using the criteria of $\mathrm{N} \geq 4$ (LOCS III standards $\mathrm{N} 4$ and N5 are similar or slightly higher than LOCS II standards N2 and N3; Table 4). Information on the prevalence of cortical and PSC opacities in the ACES study is presented only for all aged $\geq 40$, but the results suggest levels similar to those in our study, taking into account that our population was older. In a pooled analysis of studies from predominantly high-income countries (United States, European nations, Australia), ${ }^{17}$ the prevalence of cataract (using criteria similar to that in our study) showed much lower rates at comparable ages. For example, the prevalence of cataract in white women aged 55 to 59 years in the pooled analysis was $9.4 \%(95 \% \mathrm{CI}, 7.7-11.5)$ in contrast with a prevalence of $69.7 \%$ (95\%CI, 58.2-81.1) in women of that age in our population. At this age, the prevalence of aphakia/pseudophakia is low in high-income countries, and so removal of surgical cases from the estimates is not likely to affect the results. Results from studies across a range of geographical areas and ethnic groups are presented in Table 4. Population-based studies of white, Hispanic, and black (mainly African ethnicity) populations have reported prevalence levels of nuclear opacities ranging between $3 \%$ and $27 \%$, depending on the age cutoff and classification criteria, ${ }^{18-24}$ whereas studies in southeast Asia (including China and India) have reported higher prevalences. ${ }^{15,25-28}$ Of note, a study in Singapore showed that cataract surgery rates were highest in Indians and lower in Chinese. ${ }^{29}$ Cortical opacities have been reported to be more common than nuclear 
TABLE 2. Prevalence of Cataract by Type, Sex, and Age Group*

\begin{tabular}{|c|c|c|c|c|}
\hline & \multicolumn{3}{|c|}{ Age Group (y) } & \multirow[b]{2}{*}{ All Ages } \\
\hline & $50-59$ & $60-69$ & $\geq 70$ & \\
\hline \multicolumn{5}{|l|}{ Nuclear cataract (LOCS II $\geq 2$ ) } \\
\hline $\operatorname{Men}(n=507)$ & $25.8(20.7-31.7)$ & $76.8(67.6-84.0)$ & $92.6(85.4-96.4)$ & $58.8(53.6-63.7)$ \\
\hline Women $(n=564)$ & $34.6(27.8-42.0)$ & $68.6(57.4-78.0)$ & $95.7(81.2-99.2)$ & $55.1(48.6-61.5)$ \\
\hline Men and women $(n=1071)$ & $30.9(26.2-36.0)$ & $72.6(63.7-80.1)$ & $94.0(87.4-97.2)$ & $56.9(53.0-60.6)$ \\
\hline \multicolumn{5}{|l|}{ Cortical cataract (LOCS II $\geq 2$ ) } \\
\hline $\operatorname{Men}(n=508)$ & $9.6(6.8-13.4)$ & $23.2(16.2-32.1)$ & $32.2(24.6-41.0)$ & $19.5(15.1-24.8)$ \\
\hline Women $(n=553)$ & $12.8(8.3-19.3)$ & $28.0(19.5-38.4)$ & $51.1(37.7-64.4)$ & $23.5(18.5-29.3)$ \\
\hline Men and women $(n=1061)$ & $11.4(8.6-15.1)$ & $25.6(20.4-31.5)$ & $40.2(31.4-49.7)$ & $21.6(17.9-25.8)$ \\
\hline \multicolumn{5}{|c|}{ Posterior subcapsular cataract (LOCS II $\geq 2$ ) } \\
\hline $\operatorname{Men}(n=508)$ & $9.6(6.7-13.6)$ & $21.4(14.2-31.0)$ & $37.2(25.0-51.2)$ & $21.1(15.7-25.3)$ \\
\hline Women $(n=553)$ & $11.4(8.6-15.1)$ & $22.6(14.9-32.9)$ & $51.1(34.9-67.2)$ & $21.2(16.6-26.5)$ \\
\hline Men and women $(n=1061)$ & $10.7(8.5-13.3)$ & $22.0(16.1-29.3)$ & $43.1(34.4-52.2)$ & $20.6(17.0-24.8)$ \\
\hline \multicolumn{5}{|c|}{$\begin{array}{l}\text { Any cataract (LOCS } \geq 2 \text { for nuclear, cortical, or } \\
\text { PSC in worse eye) and ungradable dense } \\
\text { opacities }\end{array}$} \\
\hline $\operatorname{Men}(n=546)$ & $48.7(39.9-57.5)$ & $86.8(79.0-92.0)$ & $97.3(93.4-98.9)$ & $74.0(68.0-79.2)$ \\
\hline Women $(n=614)$ & $54.5(49.6-59.2)$ & $86.3(76.5-92.5)$ & $98.4(87.5-99.8)$ & $73.1(69.1-76.8)$ \\
\hline Men and women $(n=1160)$ & $52.0(46.5-57.4)$ & $86.6(78.9-91.7)$ & $97.8(93.6-99.3)$ & $73.5(69.4-77.3)$ \\
\hline \multicolumn{5}{|c|}{$\begin{array}{l}\text { Any cataract (LOCS } \geq 2 \text { for nuclear or cortical } \\
\text { or posterior subcapsular in worse eye) } \\
\text { including ungradable dense opacities and } \\
\text { aphakia/pseudophakia }\end{array}$} \\
\hline $\operatorname{Men}(n=583)$ & $49.1(40.4-57.9)$ & $87.6(80.1-92.5)$ & $98.3(95.2-99.4)$ & $75.8(69.9-80.9)$ \\
\hline Women $(n=651)$ & $54.8(49.9-59.5)$ & $87.8(79.2-93.1)$ & $98.7(88.9-99.9)$ & $74.8(71.3-78.0)$ \\
\hline Men and women $(n=1234)$ & $52.4(46.8-57.8)$ & $87.7(80.5-92.4)$ & $98.4(96.0-99.4)$ & $75.3(71.4-78.8)$ \\
\hline \multicolumn{5}{|c|}{$\begin{array}{l}\text { Unilateral aphakia/pseudophakia including all } \\
\text { people with a clinical exam }\end{array}$} \\
\hline $\operatorname{Men}(n=589)$ & $2.2(1.0-4.9)$ & $9.0(4.5-17.4)$ & $14.9(10.9-20.0)$ & $8.1(6.4-10.4)$ \\
\hline Women $(n=671)$ & $1.9(0.8-4.7)$ & $10.2(7.1-14.5)$ & $23.5(17.7-30.5)$ & $9.4(7.7-11.4)$ \\
\hline Men and women $(n=1260)$ & $2.0(1.0-4.2)$ & $9.7(6.9-13.4)$ & $18.9(15.9-22.3)$ & $8.8(7.7-10.1)$ \\
\hline \multicolumn{5}{|c|}{$\begin{array}{l}\text { Bilateral aphakia/pseudophakia including all } \\
\text { people with a clinical exam }\end{array}$} \\
\hline Men $(n=589)$ & $0.9(0.2-3.6)$ & $3.7(1.5-8.7)$ & $12.0(6.4-21.0)$ & $5.1(3.1-8.2)$ \\
\hline Women $(n=671)$ & $0.6(0.1-3.0)$ & $5.4(2.9-9.7)$ & $9.8(5.2-17.7)$ & $4.2(2.9-6.1)$ \\
\hline Men and women $(n=1260)$ & $0.7(0.3-1.8)$ & $4.6(2.4-8.5)$ & $11.0(7.4-16.0)$ & $4.6(3.3-6.4)$ \\
\hline
\end{tabular}

* Lens grading available in at least one eye for each type of opacity and, for two eyes in the same individual, based on worse grade of two eyes.

opacities in Hispanic Americans ${ }^{20}$ and Black Americans compared with white Americans ${ }^{19}$ and Black Caribbeans. ${ }^{18}$ In our study, nuclear opacities were observed much more frequently than were cortical or PSC opacities. In studies using the criteria of LOCS II $\geq 2$ for PSC opacities, investigators have reported prevalence levels of $\leq 5 \%$ in Hispanic Americans ${ }^{20}$ and Caribbeans of mainly African origin. ${ }^{18}$ Studies in predominantly
Chinese populations ${ }^{25-28}$ also suggest relatively low rates of PSC compared with those reported in our study and in the ACES. PSC subcapsular opacities (LOCS II $\geq 2$ ) were observed in one in five people in our study. Because of the high prevalence we observed, we performed an additional independent grading between the external experts (GM, MC) and the study graders in a random sample of 101 eyes with a PSC $\geq 1$. The

TABLE 3. Logistic Regression for Association of Cataract with Age and Sex

\begin{tabular}{|c|c|c|c|c|}
\hline & $\begin{array}{l}\text { Nuclear Cataract } \\
(\text { LOCS II } \geq 2) \\
(n=1071)\end{array}$ & $\begin{array}{l}\text { Cortical Cataract } \\
\quad(\text { LOCS II } \geq 2) \\
(n=1061)\end{array}$ & $\begin{array}{l}\text { PSC Cataract } \\
(\text { LOCS II } \geq 2) \\
(n=1061)\end{array}$ & $\begin{array}{c}\text { Any Cataract* } \\
(n=1234)\end{array}$ \\
\hline \multicolumn{5}{|l|}{ Age group (y) } \\
\hline $50-59$ & 1 & 1 & 1 & 1 \\
\hline $60-69$ & $5.9(3.6-9.8)$ & $2.7(2.0-3.5)$ & $2.4(1.5-3.7)$ & $6.5(3.7-11.3)$ \\
\hline$\geq 70$ & $35.0(15.2-80.5)$ & $5.2(3.5-7.7)$ & $6.3(4.7-8.5)$ & $57.7(21.3-156.4)$ \\
\hline \multicolumn{5}{|l|}{ Age group adjusted for sex $(y)$} \\
\hline $50-59$ & 1 & 1 & 1 & 1 \\
\hline $60-69$ & $6.0(3.6-9.9)$ & $2.8(2.1-3.7)$ & $2.4(1.6-3.7)$ & $6.6(3.7-11.6)$ \\
\hline$\geq 70$ & $35.7(15.6-81.6)$ & $5.6(3.7-8.6)$ & $6.6(4.8-9.2)$ & $59.0(21.2-164.0)$ \\
\hline \multirow[t]{2}{*}{ Women vs. men } & $0.9(0.6-1.2)$ & $1.3(0.9-1.9)$ & $1.1(0.8-1.5)$ & $0.95(0.7-1.3)$ \\
\hline & $P=0.4$ & $P=0.2$ & $P=0.7$ & $P=0.7$ \\
\hline \multirow[t]{2}{*}{ Women vs. men adjusted for age } & $1.2(0.8-1.7)$ & $1.6(1.1-2.5)$ & $1.4(0.9-2.2)$ & $1.3(0.9-1.8)$ \\
\hline & $P=0.3$ & $P=0.03$ & $P=0.1$ & $P=0.2$ \\
\hline
\end{tabular}

${ }^{*}$ LOCS II $\geq 2$ for nuclear or cortical or posterior subcapsular in worse eye and bilateral ungradable dense opacities or bilateral aphakia or pseudophakia. 


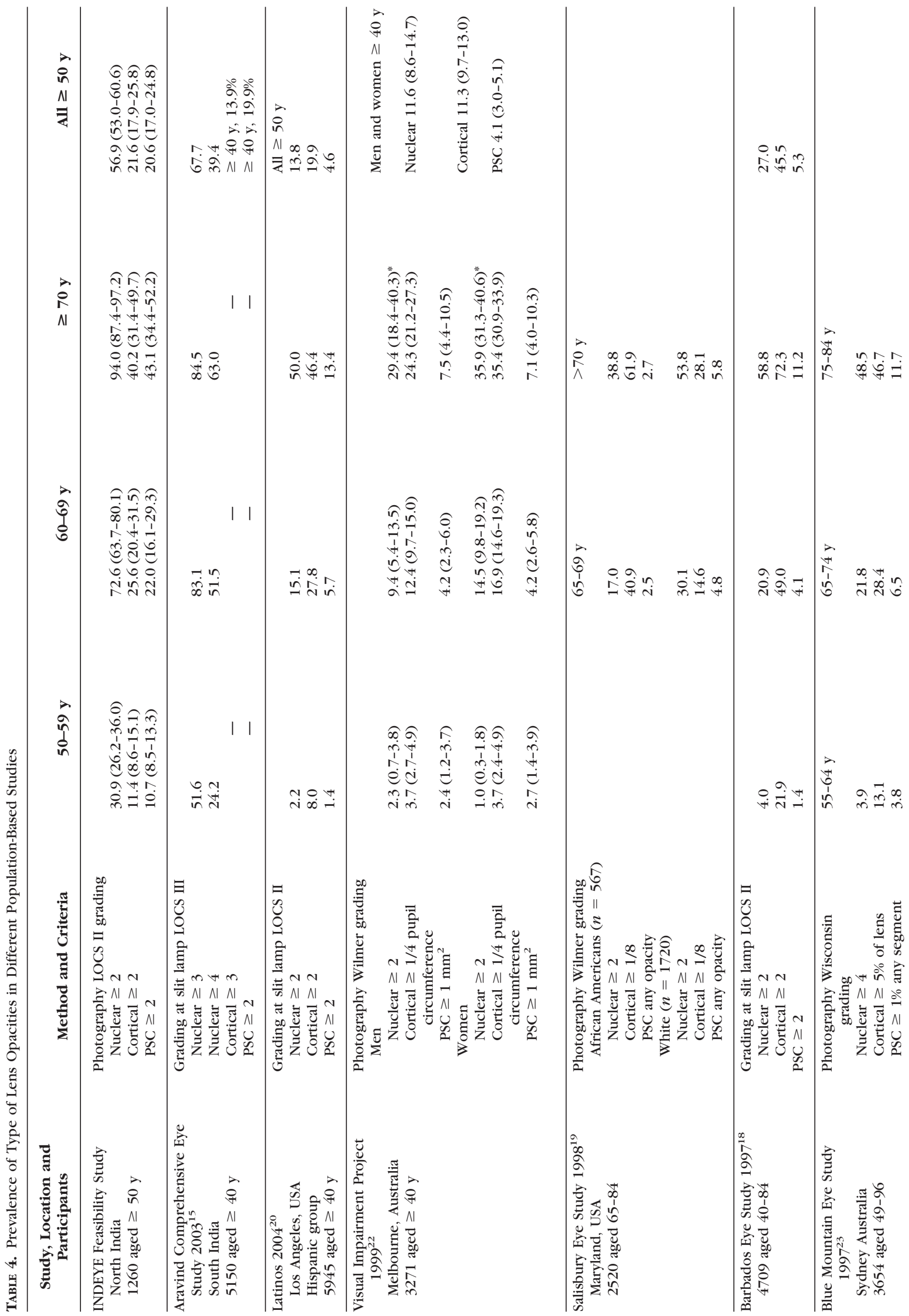




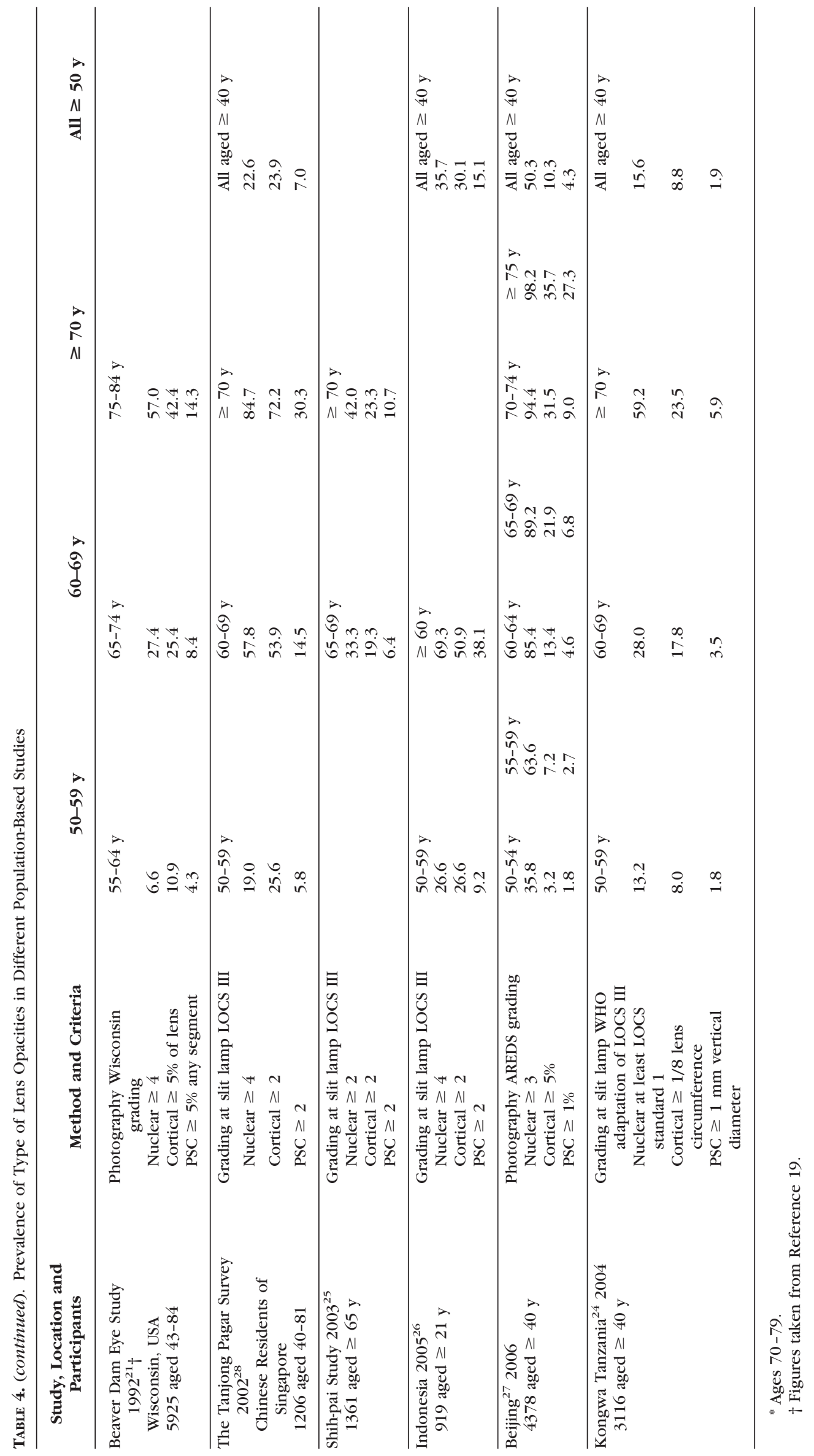


validity of the study PSC grading was confirmed by the high $\kappa$ value (0.88) obtained.

In both our study and ACES an increased prevalence of cortical opacities in women was observed of the order of between 30\% excess in ACES to 60\% in ours. In the pooled analysis, an excess association for women was also found and of a similar magnitude. ${ }^{17}$ The higher rates of untreated cataract in women may reflect more limited access to surgery but this was not found in a pooled analysis of studies, ${ }^{17}$ where there was little difference between the men and women in the prevalence of aphakia and pseudophakia. In our study, the higher prevalence in women was observed only for cortical opacities and not for nuclear or posterior subcapsular opacities, which may be more likely to interfere with vision and lead to surgery. The prevalence of bilateral aphakia and pseudophakia was similar in the men and women ( $5.1 \%$ in the men and $4.2 \%$ in the women). In other studies, an excess of cortical opacities have been reported in women $^{23,27,30,31}$; or an excess of both cortical and nuclear, ${ }^{18}$ of only nuclear, ${ }^{20,24}$ or of nuclear and PSC opacities ${ }^{26}$; or an excess of all three types. ${ }^{25,32}$

Although the study was a feasibility study conducted to obtain estimates of the prevalence of risk factors for a larger study, the $95 \%$ CIs show that the possible ranges of our results are well outside the estimates in many studies in Western populations. The explanation of the high rates of lens opacities in India remains uncertain. Exposure to ultraviolet radiation (UVR) may be a contributory factor, especially in the older rural population in which childhood and adult exposures due to outdoor work activities are likely to be very high. Although most evidence has supported an association between UVR and cortical cataract or PSC cataract, ${ }^{33}$ there is also some evidence that early-life exposures to UVR increase the risk of nuclear opacities. ${ }^{34}$ Use of indoor biomass cooking fuels $s^{35,36}$ and poor nutrition ${ }^{37,38}$ may be other relevant risk factors in this population with a high usage of biomass cooking fuels and restricted diets. The main INDEYE study which is now under way is collecting detailed information on cooking fuels and tobacco and alcohol use, 24-hour diet recall, and blood antioxidants.

\section{Acknowledgments}

The authors thank Vittorio Silvestri (Photographer, Royal Hospitals, Belfast) for training the Indeye study team; Mike Neider (Fundus Photography Reading Center, Wisconsin), for technical assistance and advice on photographic equipment and protocols; and Tara D. Pant (Rehabilitation Assistant and Survey Field Supervisor), Lalit Sanga (Survey Ophthalmologist), Hira Pant, and Kurishummutil G. Verghese (data entry operators).

\section{References}

1. Thulasiraj RD, Rahamathulla R, Saraswati A, et al. The Sivaganga eye survey: I. Blindness and cataract surgery. Ophthalmic Epidemiol. 2002;9:299-312.

2. Murthy GV, Gupta S, Ellwein LB, et al. A population-based eye survey of older adults in a rural district of Rajasthan: I. Central vision impairment, blindness, and cataract surgery. Ophthalmology. 2001;108:679-685.

3. Nirmalan PK, Thulasiraj RD, Maneksha V, et al. A population based eye survey of older adults in Tirunelveli district of south India: blindness, cataract surgery, and visual outcomes. BrJ Ophthalmol. 2002;86:505-512.

4. Dandona L, Dandona R, Srinivas M, et al. Blindness in the Indian state of Andhra Pradesh. Invest Ophthalmol Vis Sci. 2001;42:908916.

5. Murthy GV, Gupta SK, Bachani D, et al. Current estimates of blindness in India. Br J Ophthalmol. 2005;89:257-260.
6. Vaidyanathan K, Limburg H, Foster A, Pandey RM. Changing trends in barriers to cataract surgery in India. Bull World Health Organ. 1999;77:104-109.

7. Government of India. 1991 Census: State and District Profile Series, District Profile-Haryana. New Delhi, India: General OotR; 1998.

8. Chylack LT Jr, Leske MC, McCarthy D, Khu P, Kashiwagi T, Sperduto R. Lens opacities classification system II (LOCS II). Arch Ophthalmol. 1989;107:991-997.

9. StataCorp. Stata Statistical Software: Release 8.0. College Station, TX: Stata Corporation; 2003.

10. Foster A, Resnikoff S. The impact of Vision 2020 on global blindness. Eye. 2005;19:1133-1135.

11. Foster A. Cataract and "Vision 2020 - the Right to Sight" initiative. Br J Ophthalmol. 2001;85:635-637.

12. Chatterjee A, Milton RC, Thyle S. Prevalence and aetiology of cataract in Punjab. Br J Ophthalmol. 1982;66:35-42.

13. Mohan M. National Survey of Blindness-India. NPCB-WHO Report. New Delhi: Ministry of Health and Family Welfare, Government of India; 1989

14. Murthy GV, Ellwein LB, Gupta S, et al. A population-based eye survey of older adults in a rural district of Rajasthan: II. Outcomes of cataract surgery. Ophthalmology. 2001;108:686-692.

15. Nirmalan PK, Krishnadas R, Ramakrishnan R, et al. Lens opacities in a rural population of southern India: the Aravind Comprehensive Eye Study. Invest Ophthalmol Vis Sci. 2003;44: $4639-4643$.

16. Chylack LT Jr, Wolfe JK, Singer DM, et al. The Lens Opacities Classification System III. The Longitudinal Study of Cataract Study Group. Arch Ophthalmol. 1993;111:831-836.

17. Congdon N, Vingerling JR, Klein BE, et al. Prevalence of cataract and pseudophakia/aphakia among adults in the United States. Arch Ophthalmol. 2004;122:487-494.

18. Leske MC, Connell AM, Wu SY, et al. Prevalence of lens opacities in the Barbados Eye Study. Arch Ophthalmol. 1997;115: 105-111.

19. West SK, Munoz B, Schein OD, et al. Racial differences in lens opacities: the Salisbury Eye Evaluation (SEE) project. Am J Epidemiol. 1998;148:1033-1039.

20. Varma R, Torres M. Prevalence of lens opacities in Latinos: the Los Angeles Latino Eye Study. Ophthalmology. 2004;111:14491456.

21. Klein BE, Klein R, Linton KL. Prevalence of age-related lens opacities in a population. The Beaver Dam Eye Study. Ophthalmology. 1992;99:546-552.

22. McCarty CA, Mukesh BN, Fu CL, Taylor HR. The epidemiology of cataract in Australia. Am J Ophthalmol. 1999;128:446- 465.

23. Mitchell P, Cumming RG, Attebo K, Panchapakesan J. Prevalence of cataract in Australia: the Blue Mountains eye study. Ophthalmology 1997; 104:581-588.

24. Congdon N, West SK, Buhrmann RR, et al. Prevalence of the different types of age-related cataract in an African population. Invest Ophthalmol Vis Sci. 2001;42:2478-2482.

25. Hsu WM, Cheng CY, Liu JH, et al. Prevalence and causes of visual impairment in an elderly Chinese population in Taiwan: the Shihpai Eye Study. Ophthalmology. 2004;111:62-69.

26. Husain R, Tong L, Fong A, et al. Prevalence of cataract in rural Indonesia. Ophthalmology. 2005;112:1255-1262.

27. Xu L, Cui T, Zhang S, et al. Prevalence and risk factors of lens opacities in urban and rural Chinese in Beijing. Ophthalmology. 2006;113:747-755.

28. Seah SK, Wong TY, Foster PJ, et al. Prevalence of lens opacity in Chinese residents of Singapore: the tanjong pagar survey. Ophthalmology. 2002;109:2058-2064.

29. Wong TY. Cataract extraction rates among Chinese, Malays, and Indians in Singapore: a population-based analysis. Arch Ophthalmol. 2001;119:727-732.

30. Leske MC, Wu SY, Connell AM, et al. Lens opacities, demographic factors and nutritional supplements in the Barbados Eye Study. Int J Epidemiol. 1997;26:1314-1322.

31. Hiller R, Sperduto RD, Ederer F. Epidemiologic associations with nuclear, cortical, and PSC cataracts. Am J Epidemiol. 1986;124:916-925. 
32. Sperduto RD, Hiller R. The prevalence of nuclear, cortical, and posterior subcapsular lens opacities in a general population sample. Ophthalmology. 1984;91:815-818.

33. Dolin PJ. Ultraviolet radiation and cataract: a review of the epidemiological evidence. Br J Ophthalmol. 1994;78:478 - 482.

34. Neale RE, Purdie JL, Hirst LW, Green AC. Sun exposure as a risk factor for nuclear cataract. Epidemiology. 2003;14:707-712.

35. Smith KR, Mehta S. The burden of disease from indoor air pollution in developing countries: comparison of estimates. Int J Hyg Environ Health. 2003;206:279-289.
36. Pokhrel AK, Smith KR, Khalakdina A, et al. Case-control study of indoor cooking smoke exposure and cataract in Nepal and India. Int J Epidemiol. 2005;34:702-708.

37. Mohan M, Sperduto RD, Angra SK, et al. India-US case-control study of age-related cataracts. India-US Case-Control Study Group. Arch Ophthalmol. 1989;107:670-676.

38. Nirmalan PK, Robin AL, Katz J, et al. Risk factors for age related cataract in a rural population of southern India: the Aravind Comprehensive Eye Study. Br J Ophthalmol. 2004;88: 989-94. 